\title{
Metacognitive Awareness of Using Reading Strategies by TESOL Postgraduates Intakes 11 and 12 at Ho Chi Minh City Open University
}

\author{
Nguyen Thi Thu Thuy \\ Linh Trung High School, Vietnam
}

\begin{abstract}
Metacognitive awareness of reading strategies is significantly important for language learners at all levels, including TESOL postgraduates, as it can help them enhance their reading comprehension ability. However, if there is any one ignored or less frequently used strategy, reading comprehension definitely weakens. This study, therefore, aimed at investigating metacognitive awareness of using reading strategies by the TESOL postgraduates Intakes 11 and 12 at Ho Chi Minh City Open University, Vietnam. The current study adopted features of a mixed-methods research design to collect data in depth and breadth. A sample of eighty-one TESOL postgraduates Intakes 11 and 12 was recruited for the current study. Their awareness and factuality of using metacognitive strategies in reading process was elucidated through two instruments of a thirty-eight-item questionnaire and a five-question semi-structured interview. Then the questionnaire data were quantitatively analyzed and the interview data were qualitatively analyzed. The results of this study indicated that perils of using metacognitive strategies in reading process seemed to outweigh merits of this implementation. In addition, some metacognitive reading strategies were neglected by some TESOL postgraduates, that is, using context clues, guessing the text content, and critically analyzing and evaluating the text information (global group), discussing with others, self-questioning, and paraphrasing (support group). The study was closed by a brief conclusion of key findings.
\end{abstract}

Index Terms — metacognitive awareness, reading strategies, TESOL postgraduates, intakes 11 and 12

\section{INTRODUCTION}

One of the most controversial topics in the EFL reading classrooms these days is the matter of reading comprehension. In the literature, reading comprehension has been extensively set in various ways by numerous theorists. It is defined as a complex process in which a set of skills and sub-skills are employed (Cain, Oakhill, \& Bryant, 2004) to understand what is read, which is the ultimate goal of any kind of reading (Carnine, Silbert, Kame'enui, \& Tarver, 2009). In this sense, the desire of any EFL readers is to comprehend the texts intensively.

In reality, however, many EFL readers are still struggling to gain mastery over their reading comprehension problems (Kasim \& Raisha, 2017). A variety of possible problems in the EFL reading classroom can be specified such as limited vocabulary range, lexical and syntactic knowledge, inefficient reading skills, low motivation, etc. (Grabe, 1991; Cabaroglu \& Yurdaisik, 2008; Kasim \& Raisha, 2017). As a matter of fact, reading is of complexity due to various obstacles (e.g. prior knowledge, language proficiency, and metacognitive capacity) causing huge influence on the readers' reading processes and their comprehension of written texts (Karbalaei, 2010; Ismail \& Tawalbeh, 2015; Meniado, 2016). Reading comprehension, for those reasons, is uneasy for many EFL learners to achieve. In the same vein, Yukselir (2014) explicates that "reading comprehension is the result of complex interactions between text, setting, the reader, the reader's background, her reading strategies, her L1 and the L2 language, and the reader's decision making" (p. 66). Emerged from this author's definition, reading strategies are of the factors directly contributing to reading comprehension degree. Reading strategies are steps or actions purposely selected and conducted (Anderson, 1991; Carrell, Cajdusek \& Wise, 1998) in response to specific reading purposes such as acquisition, storage, and retrieval of the text information (Anderson, 1991). These are cognitive or behavioral actions (Davies, 1995; Yang, 2006; Graesser, 2007) done by readers for repairing or solving reading problems during their decoding the texts (Yang, 2006; Grabe, 2009), and then improving their reading comprehension (Graesser, 2007). In this regard, reading strategies can help readers make sense of what they are reading, and how they will do to overcome reading problems and guarantee the success of reading comprehension (Block, 1986).

In both theory and practice, pursuing recent research bodies in the arena of reading strategies is to investigate the most effective techniques or approaches the EFL readers select to manage the written texts. Readers' awareness, monitoring and regulating of these strategies while reading are called as metacognitive awareness (Anderson, 2000). Broadly, Kuhn (2000) attributes metacognitive awareness to expanding the control of reading strategies that addresses to regulate and evaluate the execution of strategies that readers know and possess. Likewise, metacognitive awareness consists of knowledge of strategies for processing texts, the ability to supervise one's own comprehension and the ability to adjust strategies when necessary (Sheorey \& Mokhtari, 2001). Many studies have broadly centralized on EFL 
readers' metacognitive awareness of reading strategies, and strategy training enabling them to perform more effective reading comprehension ability. Literally, contemporary bodies of research have documented that good readers possess their comprehensive metacognitive awareness of reading strategies, and utilize these tools effectively and reasonably so as to finish the specific given reading tasks (Ismail \& Tawalbeh, 2015). Put another way, Johansen (2013) expounds that good readers are strategic and active participants in their reading process; in contrast, weak readers having a passive tendency is to just read with suffering a severe lack of basic foundations, and they do not understand what they read. Unfortunately, many EFL learners, particularly in the Vietnamese context, almost suffer from several reading comprehension problems. Nevertheless, many Vietnamese students regardless of educational systems and/or levels, during their EFL reading activities, do not conceive and utilize reading strategies efficiently if any (Nguyen, 2018). There is no doubt that awareness and use of reading strategies has direct and consistent correlation with reading comprehension ability performed by the EFL readers.

With all above interest of the study and mentioned issues, together with there not being many studies about TESOL (Teaching English to Speakers of Other Languages) postgraduates' metacognitive awareness of reading strategies, the researcher made a decision to carry out an exploration of metacognitive awareness of utilizing reading strategies among TESOL postgraduates Intakes 11 and 12 at Ho Chi Minh City Open University (HCMCOU). The two research questions, accordingly, were devised for this study:

1. How are the TESOL postgraduates Intakes 11 and 12 at HCMCOU aware of the merits and perils of using metacognitive strategies during their reading process?

2. How do these learners actually use metacognitive strategies during their reading process?

\section{Methodology}

\section{A. Participants}

Thanks to the adoption of convenience sampling technique, the researcher recruited 81 postgraduates from TESOL11 and TESOL12 into this study, in which 42 participants belonged to TESOL11 and 39 participants belonged to TESOL12. Among these 81 participants, there were 15 males $(18.5 \%)$ and 66 males $(81.5 \%)$. The age variation was from 22 to 50 years old. Most of them achieved C1 level of CEFR (Common European Framework of Reference for Languages).

\section{B. Research Design}

The current study employed a mixed-methods design, which consists of both quantitative and qualitative research methods and approaches in a single study (Creswell \& Clark, 2011). By reason, quantitative research method can yield specific numbers that are statistically analyzed to assess the frequency and magnitude (Creswell, 2012) of metacognitive awareness of using reading strategies by TESOL postgraduates. In addition, qualitative research method can make the investigated phenomenon deeper and wider.

\section{Research Instruments}

Questionnaire: The researcher decided to use a questionnaire in the present study because this quantitative tool is time-economical as compared to other tools and the easiest method to manage with large numbers of subjects (Dörnyei, 2007). The questionnaire was comprised of two sections with the total number of 38 items. The first section with eight items pertaining to the participants' awareness of merits (Items M1-5) and pitfalls (Items 1-3) of using metacognitive strategies for their reading academic texts. These items were rated on a five-point Likert-scale ( $1=$ strongly disagree, $2=$ disagree, 3=uncertain, 4=agree, 5=strongly agree). In addition, the second section was constructed to investigate the participants' use of metacognitive strategies in reality. The content of this section was adapted from the SORS (Survey of Reading Strategies) developed by Mokhtari and Sheorey (2002) which consists of 30 items each to be rated on a five-point Likert scale ( $1=$ never use, 2=seldom use, 3=sometimes use, 4=usually use, $5=$ always use). The higher number that respondents chose, the more frequent use of the particular strategy was reflected. This questionnaire included three sub-categories of reading strategies. The first sub-category focused on Global reading strategies (GLOB) with 13 items in total labeled GLOB1-13, followed by the second sub-category associated with Problem-solving strategies (PROB) with eight items coded PROB1-8. The last sub-category was related to Support reading strategies (SUP) with nine items in total labeled SUP1-9. In overall, the questionnaire scale and four sub-scales were quite reliable when their Cronbach's Alpha values yielded by SPSS 22.0 were greater than .700 (Creswell, 2012).

Semi-structured interview: The researcher determined to deploy a semi-structured interview, which had some welldefined questions but with freedom to expand and explore in many directions (MacDonald \& Headlam, 2009), when it could triangulate the questionnaire results (Johnson, 1992). Indeed, the exploitation of triangulation can diminish the possibility of bias, and accredit the validity and reliability of the findings (Mackey \& Gass, 2005). The semi-structured interview consisted of five questions in total. The content of this semi-structured interview were highly consonant with that of the questionnaire.

\section{Data Collection and Analysis}


Questionnaire: On the agreed dates, the researcher delivered the questionnaire copies to both TESOL classes. Afterwards, the researcher realized that there were 81 questionnaire copies which were valid and acceptable. For analysis, the researcher used Statistical Package for the Social Sciences (SPSS) version 22.0 to run the descriptive statistics of the collected questionnaires, apropos of percentage (P), mean (M) and standard deviation (S.D.). Regarding the rating intervals, the researcher followed Pallant (2005)'s descriptors, including 1.00-1.80: very low (agreement/ frequency) degree; 1.81-2.60: low (agreement/ frequency) degree; 2.61-3.40: moderate (agreement/ frequency) degree; 3.41-4.20: high (agreement/ frequency) degree; and, 4.21-5.00: very high (agreement/ frequency) degree.

Semi-structured interview: The researcher recruited six participants from the target sample who voluntarily accepted to participate in the interview sessions, all of whom were coded from S1 to S6. The interview sessions took place at the united time and place so that the researcher could record whatever the interviewees shared conveniently. During this phase, the researcher used a prepared list of the questions and interviewed the students in their Vietnamese language. For analysis, the researcher complied with analytical steps suggested by Creswell (2012). Specifically, the researcher transcribed from audio texts to written texts, then translated into English, and eventually, organized interview content into the pre-determined themes and sub-themes. The first theme was peculiar to TESOL postgraduates' awareness of benefits and challenges of utilizing metacognitive strategies, while the second theme was associated with their actual utilization of metacognitive strategies in their reading process.

\section{RESULTS AND DISCUSSION}

Quantitative and qualitative analyses of the data were synchronously used to respond to the research questions deeply and widely. For quantitative analysis, the descriptive statistics such as percentage (P), mean (M) and standard deviation (S.D.) from the questionnaires were run. Additionally, qualitative data from the semi-structured interviews were thematically analyzed to illuminate the descriptive statistics.

\section{A. Research Question 1}

How are the TESOL postgraduates Intakes 11 and 12 at HCMCOU aware of the merits and perils of using metacognitive strategies during their reading process?

TABLE 1

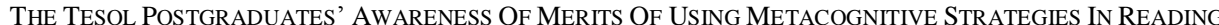

\begin{tabular}{|c|c|c|c|c|c|c|c|c|c|}
\hline Item & \multicolumn{2}{|l|}{$\begin{aligned} & \text { Merits } \\
\mathbf{N} & =\mathbf{8 1}(\mathbf{1 0 0 \%})\end{aligned}$} & \multirow{2}{*}{ 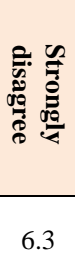 } & \multirow{2}{*}{ 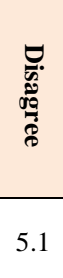 } & \multirow{2}{*}{ 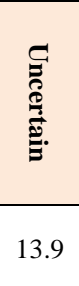 } & \multirow{2}{*}{$\begin{array}{l}\frac{\vec{b}}{80} \\
25.3\end{array}$} & \multirow{2}{*}{ 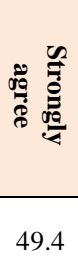 } & \multirow{2}{*}{$\begin{array}{c}\text { M } \\
4.06\end{array}$} & \multirow{2}{*}{$\begin{array}{l}\text { S.D. } \\
1.10\end{array}$} \\
\hline M1 & $\begin{array}{l}\text { Metacognitive strategies make my reading more } \\
\text { purposely through self-planning. }\end{array}$ & $\mathbf{P}(\%)$ & & & & & & & \\
\hline M2 & $\begin{array}{l}\text { Metacognitive strategies make my reading more } \\
\text { strategic through self-monitoring and self- } \\
\text { evaluating. }\end{array}$ & $\mathbf{P}(\%)$ & 2.5 & 6.3 & 12.7 & 20.3 & 58.2 & 4.25 & .99 \\
\hline M3 & $\begin{array}{l}\text { Metacognitive strategies support me to remediate } \\
\text { comprehension breakdown. }\end{array}$ & $\mathbf{P}(\%)$ & 0.0 & 0.0 & 17.7 & 27.8 & 54.4 & 4.37 & .88 \\
\hline M4 & $\begin{array}{l}\text { Metacognitive strategies improve my reading } \\
\text { comprehension ability. }\end{array}$ & $\mathbf{P}(\%)$ & 0.0 & 2.5 & 6.3 & 22.8 & 68.4 & 4.57 & .92 \\
\hline M5 & $\begin{array}{l}\text { Metacognitive strategies enhance my reading } \\
\text { motivation. }\end{array}$ & $\mathbf{P}(\%)$ & 10.1 & 7.6 & 15.2 & 26.6 & 40.5 & 3.80 & 1.02 \\
\hline & Average & $\mathbf{P}(\%)$ & 3.8 & 4.3 & 13.2 & 24.6 & 54.2 & 4.21 & .98 \\
\hline
\end{tabular}

As can be seen from Table 4.1, the majority of the participants were positively aware of the merits of using metacognitive strategies in their reading process $(M=4.21, S . D .=.98)$. In specific, three quarters of the participants advocated that metacognitive strategies could make their reading more purposely through self-planning (Item M1, 49.4\% strongly agree, $25.3 \%$ agree, $M=4.06$, S.D. $=1.10$ ). In addition, four-fifths of the response community believed that metacognitive strategies could make their reading more strategic through self-monitoring and self-evaluating (Item M2, $58.2 \%$ strongly agree, $20.3 \%$ agree, $M=4.25$, S.D. = .99). Especially, more than four-fifths of the sample posited that metacognitive strategies could support them to remediate comprehension breakdown during reading (Item M3, 54.4\% strongly agree, $27.8 \%$ agree, $M=4.37$, S.D. $=.88$ ). Thus, nearly all the participants opined that metacognitive strategies could improve their reading comprehension ability. Statistically, by the highest mean score (Item M4, M = 4.57, S.D. $=.92$ ), $68.4 \%$ and $22.8 \%$ of the response community made strong agreement and agreement, respectively. Nevertheless, only two-thirds of the entire sample found that metacognitive strategies could enhance their reading motivation (Item M5, 40.5\% strongly agree, $26.6 \%$ agree, $M=3.80$, S.D. = 1.02). 
Consistent with the questionnaire results, the interview results showed a similar tendency. When the researcher asked the first question, According to your perception, what benefits do metacognitive reading strategies bring to your reading comprehension?, all the interviewees specified advantages of using metacognitive strategies in reading process. All the six interviewees disclosed that they could make readers more active and independent and engaged and conscious in reading process since they looked like directions in the reading process (e.g., S1, S2, S4, S6), helping reading process more directive and strategic and purposeful (e.g., S1, S3, S5). Below are some extracts signifying the data presentation:

In my opinion and understanding, metacognitive reading strategies are goal-driven activities, helping me to control and monitor reading process. These strategies make me more active and independent in reading process. Q1-S1

As far as I know, metacognitive reading strategies are important to me since these strategies are functional, making me more active during reading process such as self-planning, self-regulating and self-evaluating. Q1-S4

First, a large number of the participants espoused that metacognitive strategies made their reading more purposely through self-planning and more strategic through self-monitoring and self-evaluating. Theoretically, metacognitive reading strategies as planned, intended, goal-directed, and future-oriented mental activities and processes that support readers think about, monitor and examine how they go on in completing a reading task (Pintrich, Wolters \& Baxter, 2000). Accordingly, students without metacognitive approaches are "essentially learners without direction, or opportunity to plan their learning, monitor their progress or review their accomplishments and future directions" (O’Malley \& Chamot, 1990, p. 8). Briefly, these strategies enable students to be consciously aware of how to set reading objectives and how to be effective and independent in their reading learning. In other words, the maneuvering of metacognitive reading strategies triggers readers' thinking and contributes to more thoughtful learning and better reading comprehension performance. In addition, based on the findings of the study, the metacognitive strategies also became a functional tool in remediating their comprehension breakdown and increasing their reading motivation. Indeed, metacognitive reading strategy awareness is higher order performance strand that necessitates remediation of breakdowns of comprehension failure or evaluating the success of a reading activity (Pressley \& Afflerbach, 1995, cited in Ahmadi, Ismail, \& Abdullah, 2013).

TABLE 2

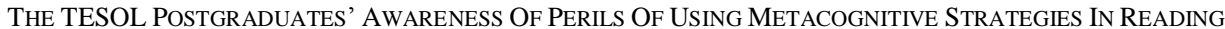

\begin{tabular}{|c|c|c|c|c|c|c|c|c|c|}
\hline Item & \multicolumn{2}{|l|}{$\begin{aligned} \text { Perils } \\
\mathbf{N}=\mathbf{8 1}(\mathbf{1 0 0} \%)\end{aligned}$} & 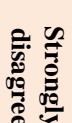 & 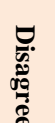 & 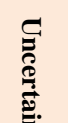 & $\stackrel{80}{8}$ & 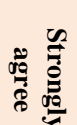 & M & S.D. \\
\hline P1 & $\begin{array}{l}\text { Good use of metacognitive strategies requires me to } \\
\text { capture what reading strategies should be used. }\end{array}$ & $\mathbf{P}(\%)$ & 0.0 & 0.0 & 19.0 & 31.6 & 49.4 & 4.30 & .78 \\
\hline $\mathbf{P 2}$ & $\begin{array}{l}\text { Good use of metacognitive strategies urges me to } \\
\text { understand how reading strategies are processed. }\end{array}$ & $\mathbf{P}(\%)$ & 0.0 & 0.0 & 22.8 & 24.1 & 53.2 & 4.30 & .77 \\
\hline P3 & $\begin{array}{l}\text { Good use of metacognitive strategies forces me to } \\
\text { know when and why reading strategies are used. }\end{array}$ & $P(\%)$ & 0.0 & 0.0 & 8.9 & 13.9 & 77.2 & 4.68 & .75 \\
\hline & Average & $\mathbf{P}(\%)$ & 0.0 & 0.0 & 16.9 & 23.2 & 59.9 & 4.43 & .77 \\
\hline
\end{tabular}

It seemed that under the TESOL postgraduates' perspectives, perils of using metacognitive strategies in reading process outweighed merits $(\mathrm{M}=4.43$, S.D. $=.77)$. More specifically, four-fifths of the respondents thought that effective use of metacognitive strategies could require them to capture what reading strategies (i.e. declarative knowledge) should be used (Item P1, M = 4.30, S.D. = .78). Numerically, there were $49.4 \%$ and $31.6 \%$ of the informants rating "strongly agree" and "agree" scales, respectively. For Item P2 (M = 4.30, S.D. = .77), beyond fourfifths of the sample postulated that effective use of metacognitive strategies could urge them to understand how reading strategies are processed (i.e. procedural knowledge). Indeed, 53.2\% and $24.1 \%$ of the TESOL postgraduates rated "strongly agree" and "agree" scales, respectively. Most strikingly, according to nearly 90 percent of the respondents avowed that effective use of metacognitive strategies could require them to know when and why reading strategies are used (i.e. conditional knowledge). Evidently, up to $77.2 \%$ of the surveyed students made strong agreement with this challenge, and 13.9\% rated "agree" scale. Hence, the mean index of Item P3 was very high $(\mathrm{M}=4.68, \mathrm{~S} . \mathrm{D} .=.75)$. Overall, none of them disputed these three difficulties in utilizing metacognitive strategies for their reading process.

Qualitatively, the interview results from the second question, What difficulties or challenges do you meet with when using metacognitive reading strategies?, also exhibited a same fashion with the questionnaire ones. All the interviewees believed that it was challenging and time-consuming to seek and identify the appropriate strategies in conformity with the given reading task types (e.g., S1, S2, S3, S4, S5 and S6). Moreover, S4 specified his case that he had to choose another strategy to continue to finish the target reading task when he had chosen the unfeasible previous one. Besides, S5 summarized the challenges of utilizing metacognitive strategies by three aspects, that is, functions, operational manners and applicable time of these strategies. Evidently, some relevant extracts are cited here: 
There are a lot of reading strategies, and the biggest challenge is that I must think and consciously select the suitable reading strategies to the given reading tasks. Q2-S2

I am usually confused to choose the possible reading strategies due to a plenty of reading strategies within similar functions. This costs much time. Furthermore, I sometimes have to try another strategy since the one I have chosen cannot really help me to resolve the reading tasks. Q2-S4

There exists a plenty of difficulties in use of metacognitive strategies in my reading process. The first one is that I need to grasp the knowledge about functions of specific reading strategies. The second one is that I need to understand the ways to activate these strategies. The last one is that I must know the time to use specific reading strategies. Q2-S5

In short, some challenges of utilizing metacognitive reading strategies were also recognized among the target response community of the questionnaire, including declarative knowledge, procedural knowledge, and conditional knowledge. Based on the interview results, the EFL learners confronted difficulties in identifying, selecting, and practicing appropriate reading strategies. The first challenge was labeled to declarative knowledge which refers to knowledge of reading strategies. Alternatively saying, effective utilization of the metacognitive strategies in reading process required them to grasp knowledge of reading strategies. In principle, the EFL learners need to prepare themselves with their individual knowledge of various reading strategies which can assist their reading process (Liu, 2013). When they possess this knowledge source sufficiently, they may select their decoding and comprehending path appropriately. The second challenge was due to procedural knowledge, in which the effective utilization of these strategies urged them to capture how to process various reading strategies. Actually, the EFL learners as readers have to sharpen their procedural knowledge because readers with a high level of procedural knowledge can utilize reading strategies more automatically and effectively to compensate for reading problems (Ahmadi, et al., 2013). The third problem in using metacognitive reading strategies was related to conditional knowledge, in which effective utilization of the target strategies forced most of them to know time and reason for employing specific reading strategies. Academically, conditional knowledge refers to "knowing when and why" to apply different strategies or actions appropriately and effectively for their reading (Liu, 2013). Readers have got to choose various strategies most suitable for each given situation in an attempt to better regulate their reading process (Ahmadi, et al., 2013). In brief, skilled readers are those who possess all declarative, procedural, and conditional knowledge about cognition. Readers need to make cognitive questions as what strategies to utilize, where, when, how, how much, how often, and why to utilize them in apprehending different texts. It is proposed by Mokhtari and Richard (2002) that "awareness and monitoring of one's comprehension processes are critically important aspects of skilled reading” (p. 249).

\section{B. Research Question 2}

How do these learners actually use metacognitive strategies during their reading process? 
TABLE 3

THE TESOL POSTGRAdUATES’ USE OF GLOBAL READING STRATEGIES

\begin{tabular}{|c|c|c|c|c|c|c|c|c|c|}
\hline Item & \multicolumn{2}{|l|}{$\begin{array}{l}\text { Global reading strategies } \\
\qquad \mathbf{N}=\mathbf{8 1}(\mathbf{1 0 0 \%})\end{array}$} & \multirow{2}{*}{$\begin{array}{l}\frac{Z}{9} \\
\frac{9}{4} \\
\end{array}$} & \multirow{2}{*}{$\begin{array}{l}\frac{\pi}{\frac{0}{2}} \\
\frac{0}{\Xi} \\
0.0\end{array}$} & \multirow{2}{*}{ 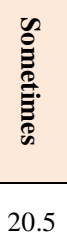 } & \multirow{2}{*}{ 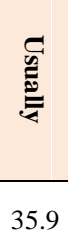 } & \multirow{2}{*}{ 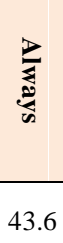 } & \multirow{2}{*}{$\begin{array}{c}\text { M } \\
\\
4.23\end{array}$} & \multirow{2}{*}{$\begin{array}{r}\text { S.D. } \\
.77\end{array}$} \\
\hline GLOB1 & Setting reading aims & $\mathbf{P}(\%)$ & & & & & & & \\
\hline GLOB2 & Activating prior knowledge & $\mathbf{P}(\%)$ & 3.8 & 11.5 & 46.2 & 29.5 & 9.0 & 3.28 & .92 \\
\hline GLOB3 & Previewing the text content & $\mathbf{P}(\%)$ & 2.6 & 7.7 & 23.1 & 42.3 & 24.4 & 3.78 & .99 \\
\hline GLOB4 & Linking text content to reading aims & $\mathbf{P}(\%)$ & 1.3 & 11.5 & 32.1 & 34.6 & 20.5 & 3.62 & .98 \\
\hline GLOB5 & $\begin{array}{l}\text { Skimming text characteristics (length, } \\
\text { organization) }\end{array}$ & $\mathbf{P}(\%)$ & 0.0 & 5.1 & 25.6 & 39.7 & 29.5 & 3.94 & .87 \\
\hline GLOB6 & Deciding what to read & $\mathbf{P}(\%)$ & 0.0 & 20.5 & 23.1 & 37.2 & 19.2 & 3.55 & 1.03 \\
\hline GLOB7 & Using tables, figures, and pictures & $\mathbf{P}(\%)$ & 0.0 & 2.6 & 28.2 & 47.4 & 21.8 & 3.88 & .77 \\
\hline GLOB8 & Using context clues & $\mathbf{P}(\%)$ & 10.3 & 19.2 & 39.7 & 23.1 & 7.7 & 2.99 & 1.08 \\
\hline GLOB9 & $\begin{array}{l}\text { Using typographical aids (bold face and } \\
\text { italics) }\end{array}$ & $\mathbf{P}(\%)$ & 0.0 & 3.8 & 34.6 & 34.6 & 26.9 & 3.85 & .87 \\
\hline GLOB10 & Critically analyzing and evaluating & $\mathbf{P}(\%)$ & 11.5 & 26.9 & 32.1 & 28.2 & 1.3 & 2.81 & 1.02 \\
\hline GLOB11 & Checking conflicting information & $\mathbf{P}(\%)$ & 5.1 & 7.7 & 32.1 & 44.9 & 10.3 & 3.47 & .96 \\
\hline GLOB12 & Guessing the text content & $\mathbf{P}(\%)$ & 10.3 & 20.5 & 43.6 & 19.2 & 6.4 & 2.91 & 1.03 \\
\hline GLOB13 & Checking guess & $\mathbf{P}(\%)$ & 10.3 & 23.1 & 42.3 & 16.7 & 7.7 & 2.88 & 1.06 \\
\hline & Average & $\mathbf{P}(\%)$ & 4.2 & 12.3 & 32.6 & 33.3 & 17.6 & 3.48 & .95 \\
\hline
\end{tabular}

As illustrated in Table 3, in the global group of reading strategies, "setting reading aims" (Item GLOB1), "skimming text characteristics" (Item GLOB5), "using tables, figures, pictures" (Item GLOB7), "using typographical aids" (Item GLOB9), and "previewing the text content" (Item GLOB3) were the most frequently practiced strategies. In details, more than three quarters of the participants frequently set their reading aims in their mind before reading (Item GLOB1, $35.9 \%$ usually, $43.6 \%$ always, $M=4.23$, S.D. $=.77$ ). Besides, prior to decoding and comprehending the target texts, beyond two-thirds of the students also frequently skimmed the text characteristics such as length or organization (Item GLOB5, 39.7\% usually, 29.5\% always, $\mathrm{M}=3.94$, S.D. $=.87$ ), along with previewing the text content (Item GLOB3, $42.3 \%$ usually, $24.4 \%$ always, $M=3.78$, S.D. = .99). During reading time, many of the surveyed students used tables, figures, pictures (Item GLOB7, 47.4\% usually, 21.8\% always, $\mathrm{M}=3.88$, S.D. = .77), as well as typographical aids (Item GLOB9, 34.6\% usually, 26.9\% always, $\mathrm{M}=3.85$, S.D. $=.87$ ) to understand the reading passages better.

By contrast, "using context clues" (Item GLOB8), "guessing the text content" (Item GLOB12), "checking guessing" (Item GLOB13), and "critically analyzing and evaluating the text information" (Item GLOB10) were the least frequently practiced reading strategies in the global group. In specific, nearly one-third of the students exploited context clues to enhance their reading comprehension (Item GLOB8, 23.1\% usually, 7.7\% always, M = 2.99, S.D. = 1.08). More remarkably, only one-fifth of the sample experienced the strategy of guessing the text content in their reading learning (Item GLOB12, 19.2\% usually, 6.4\% always, $\mathrm{M}=2.91$, S.D. = 1.03). Consequently, there was also rough onefifth of the informants checked their guess (Item GLOB13, 16.7\% usually, 7.7\% always, M = 2.88, S.D. = 1.06). Thereto, many of the respondents infrequently critically analyzed and evaluated the text information (Item GLOB10, $28.2 \%$ usually, $1.3 \%$ always, $\mathrm{M}=2.81$, S.D. $=1.02$ ).

What is more, Table 3 reveals that a smaller part of the total participants also utilized some other global strategies to some extent; for example, "linking text content to reading aims" (Item GLOB4, M = 3.62, S.D. = .98), "deciding what to read" (Item GLOB6, M = 3.55, S.D. = 1.03), "checking conflicting information" (Item GLOB11, M = 3.47, S.D. $=.96$ ), and "activating prior knowledge" (Item GLOB2, M = 3.28, S.D. = .92).

Qualitatively, to seek the reasons why the TESOL postgraduates put aside the least frequently used global strategies, the third interview question was generated, i.e. Do you frequently use the four strategies inclusive of "using context clues", "guessing the text content", "checking guessing", and "critically analyzing and evaluating the text 
information"? Why (not)? The frequency degrees were found in their responses like "sometimes" (e.g. S2, S5), "seldom" (e.g. S1, S4) or even "almost never" (e.g. S3, S6). For the most noticeable reasons, these strategies were timeconsuming and frustrating, and the interviewees had sparse background knowledge.

Theoretically, global reading strategies are a set of strategies used to establish the steps for the reading act (Mokhtari \& Reichard, 2002), helping readers select appropriate strategies and allocating resources before reading (Zare-ee, 2008). It is a good indication that a majority of the TESOL postgraduates at HCMCOU purposely established their aims in their mind before reading. Therefore, skimming text structures (Pressley \& Afflerbach, 1995), as well as reviewing a title, picture, illustration, heading to grasp the overview of the text (Almasi, 2003) also contributed to their global understanding on the given texts. Contrariwise, "using context clues", "guessing the text content", "checking guessing", and "critically analyzing and evaluating the text information" were the least frequently practiced reading strategies in this group. The reasons for this ignorance were emerged from the interview results, in which the EFL learners deemed these strategies far from their cognition ability. As a matter of fact, many readers are often deficient in linguistic input and background knowledge; yet, these strategies can lessen the negative impact of this shortage by using context clues or guessing the text content. Subsequently, their reading performance can be improved to some extent. Based on these facts, the TESOL postgraduates Intakes 11 and 12 at HCMCOU should utilize contextual clues and guesses to survive in such these cases.

TABLE 4

THE TESOL PostgraduAtes’ Use OF PROBLEM-SOlving ReAding STRATEGIES

\begin{tabular}{|c|c|c|c|c|c|c|c|c|c|}
\hline Item & \multicolumn{2}{|c|}{$\begin{array}{l}\text { Problem-solving reading strategies } \\
\qquad \mathrm{N}=\mathbf{8 1}(\mathbf{1 0 0 \% )})\end{array}$} & \multirow{2}{*}{$\begin{array}{l}\underset{3}{3} \\
\stackrel{9}{4} \\
0.0\end{array}$} & \multirow{2}{*}{$\begin{array}{l}\frac{\mathscr{\varrho}}{\varrho} \\
\frac{\varrho}{\Xi} \\
0.0\end{array}$} & \multirow{2}{*}{ 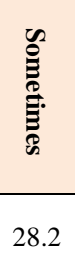 } & \multirow{2}{*}{ 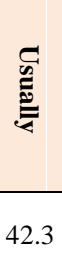 } & \multirow{2}{*}{ 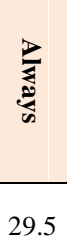 } & \multirow{2}{*}{$\begin{array}{c}\text { M } \\
4.01\end{array}$} & \multirow{2}{*}{$\begin{array}{l}\text { S.D. } \\
\\
.76\end{array}$} \\
\hline PROB1 & Reading slowly and carefully & $\mathbf{P}(\%)$ & & & & & & & \\
\hline PROB2 & Getting back & $\mathbf{P}(\%)$ & 0.0 & 2.6 & 21.8 & 50.0 & 25.6 & 3.99 & .76 \\
\hline PROB3 & Adjusting reading speed & $\mathbf{P}(\%)$ & 0.0 & 16.7 & 24.4 & 38.5 & 20.5 & 3.63 & .100 \\
\hline PROB4 & Paying closer attention & $\mathbf{P}(\%)$ & 5.1 & 9.0 & 24.4 & 6.4 & 55.1 & 3.97 & 1.28 \\
\hline PROB5 & Stopping to think & $\mathbf{P}(\%)$ & 0.0 & 0.0 & 28.2 & 39.7 & 32.1 & 4.04 & .78 \\
\hline PROB6 & Visualizing information & $\mathbf{P}(\%)$ & 0.0 & 20.5 & 28.2 & 30.8 & 20.5 & 3.51 & 1.04 \\
\hline PROB7 & Re-reading & $\mathbf{P}(\%)$ & 0.0 & 6.4 & 29.5 & 7.7 & 55.1 & 4.09 & 1.10 \\
\hline PROB8 & Guessing unknown vocabulary meaning & $\mathbf{P}(\%)$ & 2.6 & 10.3 & 28.2 & 28.2 & 30.8 & 3.74 & 1.09 \\
\hline & Average & $\mathbf{P}(\%)$ & 1.0 & 8.2 & 26.6 & 30.5 & 33.7 & 3.86 & .86 \\
\hline
\end{tabular}

As displayed in Table 4, almost all problem-solving strategies were positively practiced by the majority of the TESOL postgraduates, proved their mean values bigger than 3.40.

"Re-reading" (Item PROB7), "stopping to think" (Item PROB5), "reading slowly and carefully" (Item PROB1), "getting back when losing concentration" (Item PROB2), and "paying closer attention when the texts become more difficult" (Item PROB4) were the most frequently experienced strategies among the response community. In details, when confronting the difficult texts, a big part of the sample re-read them to accelerate their reading comprehension (Item PROB7, 7.7\% usually, 55.1\% always, $M=4.09$, S.D. = 1.10), followed by the strategy of stopping time to time to think (Item PROB5, 39.7\% usually, 32.1\% always, $\mathrm{M}=4.04$, S.D. $=.78$ ) and the strategy of reading slowly and carefully (Item PROB1, $42.3 \%$ usually, $29.5 \%$ always, $\mathrm{M}=4.01$, S.D. $=.76$ ). In addition, many of them also paid closer attention in case that the texts became more complicated (Item PROB4, 6.4\% usually, 55.1\% always, M = 3.97, S.D. = 1.28). Also, if losing concentration while reading, three quarters of the sample frequently got back on track (Item 33 , $50.0 \%$ usually, $25.6 \%$ always, $\mathrm{M}=3.99$, S.D. $=.76$ ).

Moreover, some other reading strategies in this group were preferred at medium level including "guessing unknown vocabulary meaning" (Item PROB2, M = 3.74, S.D. = 1.09), "adjusting reading speed" (Item PROB3, M=3.63, S.D. = 1.00 ), and "visualizing the text information" (Item PROB6, M = 3.51, S.D. = 1.08). 
Consonantly, the interview results obtained from the fourth question-Do you favor using problem-solving strategies in your reading process?-displayed the similar vein with the questionnaire results. In fact, all of the six interviewed participants allied their preference on use of this strategy group. They accounted that these strategies could help them to remediate comprehension breakdowns while reading. For example, S3 stated that

In my opinion, I assume that problem-solving strategies are helpful as they facilitate me to comprehend the difficult reading texts. At that time, I will do reading tasks well. Q4-S3

Overall, the results produced a positive signal that a large number of the TESOL postgraduates Intakes 11 and 12 at HCMCOU as readers emphasized monitoring strategies during their reading process, facilitating keeping the reading on track during reading, helping manage and know when things are going wrong (Ahmadi, et al., 2013). In short, the favor in problem-solving strategies indicates that the TESOL postgraduates as readers were highly aware of their reading practice and able to take actions and regulate during reading so as to fix reading difficulties.

TABLE 5

THE TESOL POSTGRAduAtes’ Use Of SUPPORT REAdING STRATEGIES

\begin{tabular}{|c|c|c|c|c|c|c|c|c|c|}
\hline Item & \multicolumn{2}{|l|}{$\begin{array}{l}\text { Support reading strategies } \\
\qquad \mathrm{N}=\mathbf{8 1}(\mathbf{1 0 0 \%})\end{array}$} & \multirow{2}{*}{$\begin{array}{l}\mathbf{Z} \\
\frac{a}{2} \\
9\end{array}$} & \multirow{2}{*}{$\begin{array}{l}\frac{\mathscr{\varrho}}{\varrho} \\
\frac{\varrho}{\Xi} \\
9.0\end{array}$} & \multirow{2}{*}{ 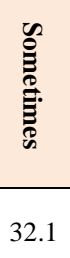 } & \multirow{2}{*}{ 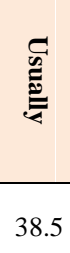 } & \multirow{2}{*}{ 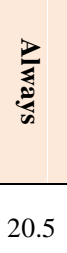 } & \multirow{2}{*}{$\begin{array}{c}\text { M } \\
\mathbf{3 . 7 1}\end{array}$} & \multirow{2}{*}{$\begin{array}{r}\text { S.D. } \\
\\
.90\end{array}$} \\
\hline SUP1 & Taking notes while reading & $\mathbf{P}(\%)$ & & & & & & & \\
\hline SUP2 & Reading aloud & $\mathbf{P}(\%)$ & 0.0 & 3.8 & 21.8 & 34.6 & 39.7 & 4.10 & .88 \\
\hline SUP3 & Summarizing information & $\mathbf{P}(\%)$ & 6.4 & 16.7 & 37.2 & 25.6 & 14.1 & 3.24 & 1.10 \\
\hline SUP4 & Discussing with others & $\mathbf{P}(\%)$ & 11.5 & 23.1 & 29.5 & 32.1 & 3.8 & 2.94 & 1.09 \\
\hline SUP5 & Underlining or circling information & $\mathbf{P}(\%)$ & 2.6 & 10.3 & 29.5 & 29.5 & 28.2 & 3.71 & 1.07 \\
\hline SUP6 & Using reference materials & $\mathbf{P}(\%)$ & 0.0 & 0.0 & 23.1 & 39.7 & 37.2 & 4.14 & .77 \\
\hline SUP7 & Paraphrasing & $\mathbf{P}(\%)$ & 17.9 & 32.1 & 32.1 & 17.9 & 0.0 & 2.50 & .99 \\
\hline SUP8 & Going back and forth to find idea relationships & $\mathbf{P}(\%)$ & 7.7 & 6.4 & 28.2 & 29.5 & 28.2 & 3.64 & 1.18 \\
\hline SUP9 & Asking myself questions & $\mathbf{P}(\%)$ & 7.7 & 26.9 & 39.7 & 19.2 & 6.4 & 2.90 & 1.01 \\
\hline & Average & $\mathbf{P}(\%)$ & 6.0 & 14.3 & 30.4 & 29.6 & 19.8 & 3.43 & 1.00 \\
\hline
\end{tabular}

As can be observed from Table 5, the majority of the TESOL postgraduates utilized the support reading strategies at a quite high level $(\mathrm{M}=3.43$, S.D. = 1.00). To begin with, "using reference materials" (Item SUP6), "reading aloud" (Item SUP2), "taking notes" (Item SUP1), and "underlining or circling information" (Item SUP5) were the most frequently experienced by the large number of the TESOL postgraduates in their reading process. Statistically, three quarters of the entire sample admitted that they used reference materials to support their academic reading comprehension (Item SUP6, 39.7\% usually, 37.2\% always, M = 4.14, S.D. = .77), followed by reading aloud strategy (Item SUP2, 34.6\% usually, 39.7\% always, $M=4.10$, S.D. = .88). Furthermore, while reading, nearly three-fifths of the informants took their notes (Item 40, 38.5\% usually, 20.5\% always, M =3.71, S.D. = .90), or underlined or circled their main text information (Item $44,29.5 \%$ usually, $28.2 \%$ always, $M=3.71$, S.D. $=1.07$ ).

On the contrary, it seemed that a big portion of the response community ignored "discussing with others" (Item SUP4, $32.1 \%$ usually, $3.8 \%$ always, $\mathrm{M}=2.94$, S.D = 1.09), "asking myself questions" (Item SUP9, 19.2\% usually, 6.4\% always, $\mathrm{M}=2.90$, S.D. = 1.01), as well as "paraphrasing" (Item SUP7, 17.9\% usually, 0.0\% always, M = 2.50, S.D $=.99$ ).

Besides, during reading time, only a smaller part of the sample went back and forth to find the relationships among text ideas (Item SUP8, M = 3.64, S.D. = 1.18) and summarized the text information (Item SUP3, M = 3.24, S.D. = 1.10).

The interview results of the fifth question-Do you frequently use three strategies inclusive of "discussing with others", "asking myself questions", and "paraphrasing"? Why (not)?-triangulated the questionnaire results. To the first part of this question, two interviewees (e.g. S5, S6) chose the "discussing with others" strategy; two interviewees (e.g. S1, S4) frequently practiced the strategy of asking myself questions; and, only one interviewee (e.g. S4) were fond 
of paraphrasing. To the second part of this question, this unexpected dilemma could be expounded that the participants were unfamiliar with self-raising some relevant questions during their reading; at the same time, they were afraid that paraphrasing the whole text or discussing with their classmates would cost much time.

On one hand, "using reference materials", "reading aloud", "taking notes", "underlining or circling information" were the most frequently experienced by the large majority of the TESOL postgraduates in their reading. In other words, these graduates were cognitively aware of supporting tools to sustain their flow of reading comprehension (Mokhtari \& Reichard, 2002). On the other hand, it seemed that a big portion of the response community ignored "discussing with others", "asking myself questions", and "paraphrasing". However, in order to understand the texts better, these TESOL postgraduates Intakes 11 and 12 at HCMCOU should discuss with their classmates or teachers to clarify or exchange their understanding in a comfortable way. During reading process, in addition, they need to pose questions on the texts by themselves and then find the answers or paraphrase the texts in their own words. Indeed, the students need to read the whole text, comprehend it and then summarize it by their own words. Alternatively saying, until the students grasp the given texts, they are able to paraphrase and vice versa. Furthermore, while reading, these readers may face conflicting or complicated information. If they pose themselves with some questions and then answer by themselves, their reading comprehension is accordingly increased. It is believed that when they practice these strategies more frequently, their reading comprehension level may be much enhanced.

Generally speaking, it was obvious that the most frequent use of the metacognitive reading strategies was eventually found to be problem-solving group $(\mathrm{M}=3.86$, S.D. $=.86)$, followed by global reading group $(\mathrm{M}=3.48, \mathrm{~S} . \mathrm{D} .=.95)$, and then support reading group $(\mathrm{M}=3.43$, S.D. $=1.00)$. Specifically, as evidenced in Chart 1 below, approximately twothirds of the target sample (33.7\% always, $30.5 \%$ usually) frequently practiced problem-solving strategies; meanwhile, only around a half of the response community (50.9\% and $49.4 \%$ ) favored global strategies (17.6\% always, $33.3 \%$ usually) and support strategies (19.8\% always, $29.6 \%$ usually) in their reading process, respectively.

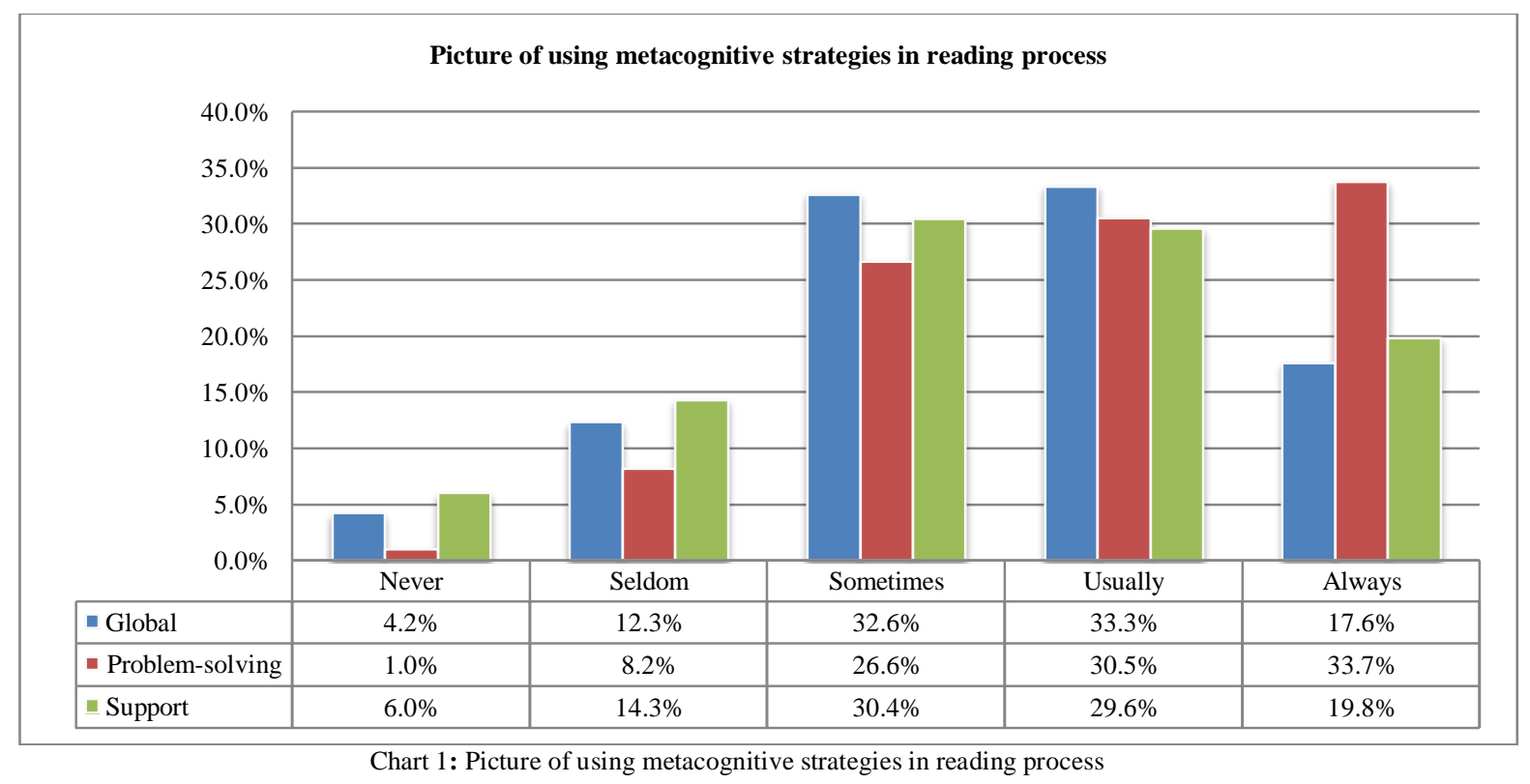

\section{CONCLUDING MARKS}

Although this study faced some limitations such as the time restriction for carrying out the study (e.g. only two months) and the small number of the participants (e.g. 81 TESOL postgraduates), it also catalyzed remarkable findings as follows.

In terms of the participants' metacognitive awareness of reading strategies, these strategies could make their reading more purposely through self-planning and more strategic through self-monitoring and self-evaluating. Besides, these reading strategies could make readers more active and independent and motivated and conscious in reading process since they looked like directions in the reading process helping reading process more directive and strategic and purposeful. Nevertheless, some challenges of utilizing metacognitive strategies in reading process were also recognized among the target response community to the questionnaire, including declarative knowledge, procedural knowledge, and conditional knowledge. In specific, many TESOL postgraduates confronted with difficulties in identifying, selecting, and practicing appropriate reading strategies.

In respect of the real picture of deploying metacognitive strategies in academic reading process, problem-solving strategies were prominently utilized among the TESOL postgraduates rather than other groups including global strategies and supporting strategies. In specific, almost all problem-solving strategies were favorably practiced by the 
majority of the students such as re-reading, stopping to think, reading slowly and carefully, getting back when losing concentration, and paying closer attention. In addition, setting reading aims, skimming text characteristics, and previewing the text content were the most frequently practiced global strategies, while using context clues, guessing the text content, and critically analyzing and evaluating the text information were the least frequently practiced reading strategies of this group. Likewise, using reference materials, reading aloud, taking notes, and underlining or circling information were the most frequently exploited supporting strategies instead of discussing with others, self-questioning, and paraphrasing.

\section{REFERENCES}

[1] Anderson, N. J. (1991). Individual differences in strategy use in second language reading and testing. The Modern Language Journal, 75(4), 464-472.

[2] Alderson, J. C. (2000). Assessing reading. Cambridge: Cambridge University Press.

[3] Ahmadi, M. R., Ismail, H. N., \& Abdullah, M. K. K. (2013). The importance of metacognitive reading strategy awareness in reading comprehension. English Language Teaching; 6(10), 235-244.

[4] Almasi, J. F. (2003). Teaching strategic process in reading. New York, NY: The Guilford Press.

[5] Block, E. (1986). The comprehension strategies of second language readers. TESOL Quarterly, 20(3), 463-494.

[6] Cabaroglu, N. \& Yurdaisik, A. (2008). University instructors' views about and approaches to reading instruction and reading strategies. The Reading Matrix, 8(2), 133-154.

[7] Cain, K., Oakhill, J., \& Bryant, P. (2004). Children's reading comprehension ability: Concurrent prediction by working memory, verbal ability, and component skills. Journal of Educational Psychology, 96(1), 31-42.

[8] Carnine, D., Silbert, J., Kame'enui, E. J., \& Tarver, S. G. (2009). Direct instruction reading (5th ed.). Upper Saddle River, NJ: Merrill/Pearson Education.

[9] Carrell. P., Gajdusek, L. \& Wise, T. (1998). Metacognition and EFL/ESL reading. Instructional Science, 26, 97-112.

[10] Creswell, J. W. (2012). Educational research: Planning, conducting, and evaluating quantitative and qualitative research (4th ed.). Boston: Pearson Education.

[11] Creswell, J. W. \& Clark, V. L. P. (2011). Designing and conducting mixed methods research. Los Angeles: SAGE Publications.

[12] Davies, F. (1995). Introducing reading. London: Penguin Books.

[13] Dörnyei, Z. (2007). Research methods in applied linguistics. Oxford, UK: Oxford University Press.

[14] Grabe, W. (1991). Current developments in second language reading research. TESOL Quarterly, 25(3), 375-406.

[15] Grabe, W. (2009). Reading in a second language: Moving from theory to practice. New York: Cambridge University Press.

[16] Graesser, A. C. (2007). An introduction to strategic reading comprehension. In D. S. McNamara (Eds.), Reading Comprehension: Theories, Interventions, and Technologies (pp. 3-26). Lawrence Erlbaum Associates: New York.

[17] Ismail, N. M., \& Tawalbeh, T. I. (2015). Effectiveness of a metacognitive reading strategies program for improving low achieving EFL readers. International Education Studies, 8(1), 71-81.

[18] Johansen, E. K. N. (2013). Reading strategies in upper secondary school. How and to what extent are reading strategies taught and used in Norwegian upper secondary schools? (Unpublished master's thesis). Norway: University of Oslo.

[19] Johnson, D. M. (1992). Approaches to research in second language learning. New York: Longman.

[20] Kasim, U., \& Raisha, S. (2017). EFL students' reading comprehension problems: Linguistic and non-linguistic complexities. English Education Journal (EEJ), 8(3), 308-321.

[21] Karbalaei, A. (2010). A comparison of the metacognitive reading strategies used by EFL and ESL Readers. The Reading Matrix, 10(2), 165-180.

[22] Kuhn, D. (2000). Metacognitive development. Current Directions in Psychological Science, 9, 178-181.

[23] Liu, P-Y. (2013). Taiwanese first year university EFL learners' metacognitive awareness and use of reading strategies in learning to read: Proficiency levels and text types (Unpublished doctoral thesis). UK: University of Exeter.

[24] Macdonald, S., \& Headlam, N. (2009). Research methods handbook. UK: Centre for Local Economic Strategies.

[25] Mackey, A. \& Gass, S.M. (2005). Second language research: Methodology and design. Mahwah, NJ: Lawrence Erlbaum.

[26] Meniado, J. C. (2016). Metacognitive reading strategies, motivation, and reading comprehension performance of Saudi EFL students. English Language Teaching, 9(3), 117-126.

[27] Mokhtari, K., \& Reichard, C. (2002). Assessing students' metacognitive awareness of reading strategies. Journal of Educational Psychology, 94(2), 249-259.

[28] Mokhtari, K., \& Sheorey, R. (2002). Measuring ESL students' awareness of reading strategies. Journal of Developmental Education, 25(3), 2-10.

[29] Nguyen, T. B. T. (2018). Reading strategies used by Vietnamese EFL and ESL university students. VNU Journal of Foreign Studies, 34(2), 111-124.

[30] O’Malley, J. M. \& Chamot, A. V. (1990). Learning strategy in second language acquisition, Cambridge: Cambridge University Press.

[31] Pallant, J. (2005). SPSS survival guide a step by step guide to data analysis using SPSS for Windows. New York: Open University Press.

[32] Pintrich, R. R., Wolters, C. A., \& Baxter, G. P. (2000). Assessing metacognition and self-regulated learning. In G. Shraw, \& J. C. Impara (Eds.), Issues in the measurement of metacognition (pp. 43-97). Lincoln, NE: Buros Institute of Mental Measurements.

[33] Sheorey, R., \& Mokhtari, K. (2001). Coping with academic materials Differences in the reading strategies of native and nonnative readers. System, 29, 431-449.

[34] Yang, Y. (2006). Reading strategies or comprehension monitoring strategies? Reading Psychology, 27, 313-343.

[35] Yukselir, C. (2014). An investigation into the reading strategy use of EFL prep-class students. Social and Behavioral Sciences Journal, 158, 65-72. 
[36] Zare-ee, A. (2008). The relationship between cognitive and meta-cognitive strategy use and EFL reading achievements. Faculty of Foreign Language and Literature, Islamic Azad University, Roudehen Branch, Tehran, Iran.

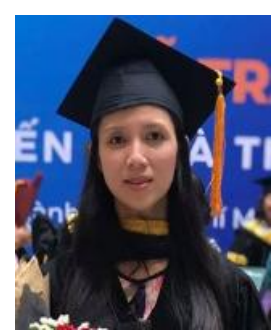

Thuy T. T. Nguyen was born in Binh Phuoc province of Vietnam on November, 8, 1983. She got her B.A. degree in English Language from HUFLIT university of Vietnam in 2007. In 2018, she earned her M.A. degree in TESOL from Ho Chi Minh City Open University, Vietnam. She has been teaching English for over 12 years at a vocational school. Currently, she works as an English teacher at Linh Trung high school of Ho Chi Minh City, Vietnam. Her research interest includes learner autonomy, TESOL methodology and educational management. 